\title{
Kainate Modulates Presynaptic GABA Release from Two Vesicle Pools
}

\author{
Seena S. Mathew, Lucas Pozzo-Miller, and John J. Hablitz \\ Department of Neurobiology and Evelyn F. McKnight Brain Institute, University of Alabama at Birmingham, Birmingham, Alabama 35294
}

Inhibitory control of local neuronal circuits is critical for prefrontal cortical functioning. Modulation of inhibitory circuits by several neuromodulators has been demonstrated, but the underlying mechanisms are unclear. Neuromodulator effects on synaptic vesicle recycling have received little attention. Controversy also exists whether different pools of synaptic vesicles underlie spontaneous and activity-dependent vesicle recycling. We therefore investigated the effects of kainate receptor activation on GABA release in rat prefrontal neocortex using electrophysiological and styryl dye imaging techniques in acute neocortical slices. Electrophysiological studies demonstrated that activation of kainate receptors increased the frequency, but not the amplitude of miniature IPSCs, suggesting a presynaptic action. Using styryl dye staining and multiphoton excitation microscopy, we visualized vesicular release from inhibitory GABAergic terminals in prefrontal cortical slices and demonstrate that kainate facilitates GABA release from presynaptic terminals. Our findings also indicate the presence of two pools of GABA-containing vesicles within inhibitory terminals. Kainate modulates both pools but only when vesicles are endocytosed and exocytosed by matching protocols of dye loading, i.e., spontaneous or evoked afferent activity.

Key words: neocortex; kainate; GABA; vesicular release; FM1-43; inhibition; multiphoton excitation microscopy; brain slices

\section{Introduction}

Local neocortical circuits are formed by synaptic connections between pyramidal cells and GABAergic inhibitory interneurons (Braitenberg and Schuz, 1991; Douglas et al., 1995). Circuits containing recurrent excitatory connections, like those among layer II/III pyramidal neurons, are inherently unstable (Douglas et al., 1995; Sompolinsky and Shapley, 1997; Nelson and Turrigiano, 1998). Feedback inhibition via GABAergic interneurons provides a stabilizing influence and prevents runaway excitation (Galarreta and Hestrin, 1998; Varela et al., 1999). Inhibitory synapses are subject to modulation by a variety of neurotransmitters, including dopamine (Zhou and Hablitz, 1999a) and serotonin (Zhou and Hablitz, 1999b). Synaptically released glutamate enhances IPSCs (IPSCs) in neocortex via kainate receptors (KARs) (Min et al., 1999; Mathew and Hablitz, 2003, 2005). Understanding the mechanisms of IPSC modulation is critical because inhibition is important for the temporal flow of cortical information (Constantinidis et al., 2002).

KARs have been found presynaptically in the hippocampus, localized within the active zone of synapses poised to modulate synaptic events (Pinheiro et al., 2005). Postsynaptic recordings of miniature IPSCs also indicate that kainate activates presynaptic receptors on GABAergic nerve terminals in hippocampus

Received Aug. 9, 2007; revised Nov. 16, 2007; accepted Dec. 3, 2007

This work was supported by National Institutes of Health Grants R01NS22373, P30-NS47466, P30-HD38985, and P30-NS57098. We thank A. Yildirim (Vision Science Center, University of Alabama at Birmingham) for building the external PMT detector for the multiphoton excitation microscope, K. Alison Margolies for technical assistance, and Dr. J. Wadiche for critical reading of this manuscript.

Correspondence should be addressed to Dr. John J. Hablitz, Department of Neurobiology, University of Alabama at Birmingham, Birmingham, AL 35294. E-mail: jhablitz@uab.edu.

DOI:10.1523/JNEUROSCI.3625-07.2008

Copyright $\odot 2008$ Society for Neuroscience $\quad$ 0270-6474/08/280725-07\$15.00/0
(Rodriguez-Moreno et al., 1997; Frerking et al., 1999; Mulle et al., 2000; Cossart et al., 2001) and neocortex (Ali et al., 2001; Ren et al., 2007). Recent advances in imaging technology have made it possible to directly monitor spontaneous and activity-dependent synaptic vesicle recycling in brain slices using the styryl dye FM1-43 (Stanton et al., 2001; Zakharenko et al., 2001; Brager et al., 2003; Axmacher et al., 2004). Neurotransmitter release, mediated by synaptic vesicle exocytosis at the active zone of a synapse, requires fusion of synaptic vesicles with the nerve terminal plasma membrane. This membrane is then retrieved and recycled for successive rounds of transmitter release (Scheller, 1995). Brief applications of high $\mathrm{K}^{+}$solutions (Ceccarelli et al., 1988), short action potential trains (Pyle et al., 2000) and hyperosmotic solutions stimulate neurotransmitter release from the same vesicle pool, the readily releasable pool (RRP). The RRP is operationally defined as those quanta that are released with application of hypertonic solutions (Stevens and Tsujimoto, 1995; Rosenmund and Stevens, 1996). Physiologically, this pool is engaged during the transient burst of exocytotic activity after electrical stimulation and the resulting increase in intracellular $\mathrm{Ca}^{2+}$ (Schneggenburger et al., 1999). During repetitive afferent nerve activity, the RRP is depleted and vesicles are then mobilized to the active zone from a "reserve" pool (RP) (Elmqvist and Quastel, 1965; Richards et al., 2003). Differential effects of neuromodulators, such as BDNF, on specific vesicle pools have been reported (Tyler et al., 2006), but direct presynaptic actions of kainate (KA) on vesicular transmitter release have not been determined.

Spontaneous quantal neurotransmitter release, like that mediating miniature IPSCs, is thought to occur through low probability random fusion of the same synaptic vesicles released after action potential-dependent $\mathrm{Ca}^{2+}$ influx, but in the absence of such an external trigger (Murthy and Stevens, 1999; Prange and 
Murphy, 1999). However, a debate has emerged recently as to whether spontaneously endocytosing vesicles belong to a separate pool of vesicles that are "reluctant" to release after electrical stimulation (Sara et al., 2005) or to the same pool that underlies evoked release (Groemer and Klingauf, 2007). These studies both examined excitatory glutamatergic synapses between cultured hippocampal neurons. In the present study, we used multiphoton excitation microscopy of FM1-43 fluorescence to directly examine KAR modulation of both spontaneous and activitydependent vesicular transmitter release at inhibitory synapses in acute slices from prefrontal cortex.

\section{Materials and Methods}

Slice preparation

Neocortical slices from 18- to 25-d-old rats were prepared as described previously (Gonzalez-Islas and Hablitz, 2001). Animals were handled and housed according to the National Institutes of Health Committee on Laboratory Animal Resources. All experimental protocols were approved by the University of Alabama at Birmingham Institutional Animal Care and Use Committee. Every effort was made to minimize pain and discomfort. Briefly, rats of either sex were anesthetized with ketamine (100 $\mathrm{mg} / \mathrm{kg}$ ) and rapidly decapitated. The brain was quickly removed and placed in ice-cold oxygenated saline. A block of prefrontal cortex was prepared and cut in 300- $\mu \mathrm{m}$-thick slices using an Oxford Series 1000 Vibratome. Slices were stored at $37^{\circ} \mathrm{C}$ for $1 \mathrm{~h}$ before recording or imaging.

\section{Solutions and chemicals}

The extracellular saline contained (in $\mathrm{mm}$ ) $125 \mathrm{NaCl}, 3.5 \mathrm{KCl}, 1.25$ $\mathrm{NaH}_{2} \mathrm{PO}_{4}, 2.5 \mathrm{CaCl}_{2}, 1.3 \mathrm{MgSO}_{4}, 26 \mathrm{NaHCO}_{3}$, and 10 D-glucose, $\mathrm{pH} 7.3$ by bubbling with $95 \% \mathrm{O}_{2} / 5 \% \mathrm{CO}_{2}$. For IPSC recordings, the intracellular solution contained (in mM) $135 \mathrm{KCl}, 0.5 \mathrm{EGTA}, 2 \mathrm{Mg}$-ATP, $0.2 \mathrm{NaGTP}$ and $10 \mathrm{HEPES}$, and $\mathrm{pH}$ was adjusted to 7.3 with $1 \mathrm{~m} \mathrm{KOH}$, and osmolarity adjusted to $290 \mathrm{mOsm}$ with sucrose. Miniature IPSCs were pharmacologically isolated by blocking AMPA, NMDA, and $\mathrm{GABA}_{\mathrm{B}}$ receptors with 4-(8-methyl-9H-1,3-dioxolo[4,5-h][2,3]benzodiazepine-5-yl)benzenamine (GYKI52466; $50 \mu \mathrm{M})$, D-APV $(50 \mu \mathrm{M})$, and $(2 S)-(+)-5,5-$ dimethyl-2-morpholineacetic acid (SCH50911;2 $\mu \mathrm{M}$ ), respectively. TTX $(1 \mu \mathrm{M})$ was added to block sodium-dependent action potentials. The intracellular solution for recording excitatory synaptic currents contained (in mM) $125 \mathrm{~K}$-gluconate, $10 \mathrm{KCl}, 10 \mathrm{HEPES}, 2 \mathrm{Mg}$-ATP, 0.2 Na-GTP, and 0.5 EGTA. Bicuculline methiodide (BIC) $(10 \mu \mathrm{M})$ and SCH50911 were present during all experiments to block $\mathrm{GABA}_{\mathrm{A}}$ receptor and $\mathrm{GABA}_{\mathrm{B}}$ receptors, respectively. Chemicals for experiments were purchased from Fisher Chemicals (Fairlawn, NJ) except for adenosine, biocytin, BIC (Sigma, St. Louis, MO), HEPES, and EGTA (Calbiochem, La Jolla, CA). APV, GYKI52466, TTX, and SCH50911 were purchased from Tocris Cookson (Ellisville, MO).

\section{Whole-cell recording and analyses}

For whole-cell patch-clamp recordings, individual cells were visualized using a Leica (Bannockburn, IL) DM LFSA microscope equipped with a $40 \times, 0.75$ numerical aperture long-working distance water-immersion objective and infrared illumination. Neurons were imaged using an infrared-sensitive video camera (Newvicon C2400-07-C; Hamamatsu, Hamamatsu, Japan). Pyramidal neurons in layers II/III were identified by their depth below the pial surface, pyramidal shape, prominent apical dendrites and regular spiking properties. Whole-cell recordings were made at $32^{\circ} \mathrm{C}$. Patch pipettes were pulled from borosilicate glass capillaries on a Narishige (Tokyo, Japan) Model PP-83 puller and had resistances of 3-4 M Series resistance ranged from 4 to $12 \mathrm{M} \Omega$ and was compensated. Recordings were made in voltage-clamp with an Axopatch-1B amplifier, controlled by Clampex 8.0 software via a Digidata 1322A interface (Molecular Devices, Sunnyvale, CA). Miniature IPSCs were analyzed using Mini Analysis program (Synaptosoft, Leonia, NJ). Data are expressed as mean \pm SEM. Statistical analyses of response amplitudes before, during, and after drug applications were evaluated using a twotailed Student's $t$ test. a

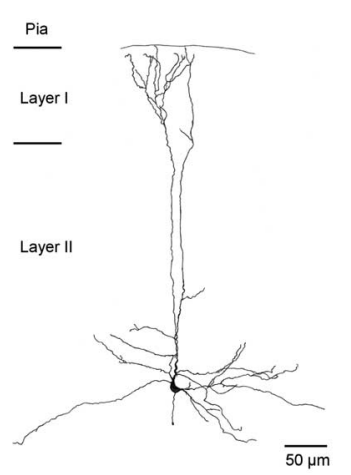

d Control
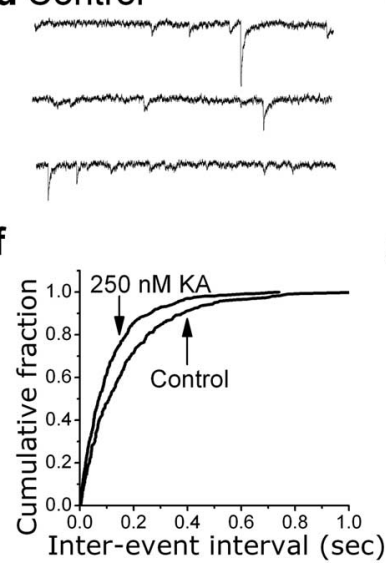

g
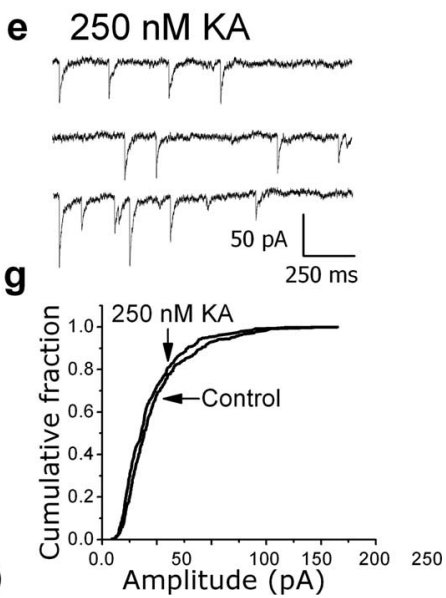

Figure 1. Effects of KA on evoked IPSCs and mIPSCs recorded from layer II/III pyramidal cells. $\boldsymbol{A}$, Camera lucida reconstruction of a biocytin-labeled pyramidal cell located in layer III. $\boldsymbol{B}, \boldsymbol{C}$, IPSCs evoked before and after, respectively, bath application of $250 \mathrm{~nm}$ KA. Each trace is an average of 10 trials. KA increased the amplitude of evoked IPSCS. D, E, Representative records of mIPSCs from a layer II/III pyramidal neuron before and after bath application of $250 \mathrm{~nm} \mathrm{KA}$. An increase in frequency is readily apparent. $F, G$, Cumulative probability plots of mIPSC interevent intervals and amplitudes, respectively. The leftward shift in the interevent intervals in the presence of $250 \mathrm{~nm}$ kainate indicates an increase in mIPSC frequency (control, $1.35 \pm 0.3 \mathrm{~Hz}$ vs $\mathrm{KA}, 2.46 \pm 0.7 ; p=0.01 ; n=13$ ). mIPSC amplitudes were not affected by KA, suggesting a presynaptic mechanism (control, $39.99 \pm 5.4$ vs KA, 39.07 $\pm 6.0 ; p=0.09 ; n=13$ ).

\section{FM1-43 staining and destaining}

All experiments were conducted in the presence of $50 \mu \mathrm{M} \mathrm{D}-\mathrm{APV}, 50 \mu \mathrm{M}$ GYKI52644, and $2 \mu \mathrm{M}$ SCH50911 to prevent effects of recurrent activity during stimulation. Staining and destaining with FM1-43 was accomplished at $32^{\circ} \mathrm{C}$ by three methods as follows.

High $\mathrm{K}^{+}$-induced depolarization. Presynaptic boutons were loaded with FM1-43 $(5 \mu \mathrm{M})$ by a $45 \mathrm{~s}$ application of a solution containing $40 \mathrm{~mm}$ $\mathrm{K}^{+}$at $32^{\circ} \mathrm{C}$. Normal recording solution containing $50 \mu \mathrm{M} \mathrm{D}-\mathrm{APV}, 50 \mu \mathrm{M}$ GYKI52644, and $2 \mu \mathrm{M} \mathrm{SCH} 50911$ was then applied for $30 \mathrm{~min}$ to washout FM1-43 from the slice. Depolarization-dependent destaining of FM1-43 was evoked by bath application of saline containing $80 \mathrm{~mm} \mathrm{~K}^{+}$.

Electrical stimulation. Slices were transferred to the imaging chamber, submerged, and superfused continuously at $2-4 \mathrm{ml} / \mathrm{min}$ with saline at $32^{\circ} \mathrm{C}$. Electrical stimulation was applied with a bipolar stimulating electrode (a twisted pair of $25 \mu \mathrm{m}$ Formvar-insulated nichrome wires) positioned 40-60 $\mu \mathrm{m}$ away from the field of interest. FM1-43 (5 $\mu \mathrm{M})$ was present for $60 \mathrm{~s}$ before stimulation. Stimulation-induced staining was achieved using $10 \mathrm{~Hz}$ stimulation for $90 \mathrm{~s}$, and FM1-43 remained for an additional minute after the stimulation ended, followed by a $30 \mathrm{~min}$ washout period. After imaging a period of baseline FM1-43 fluorescence intensity (11 s) (see below), FM-labeled puncta were destained with a 10 $\mathrm{Hz}$ train of stimulation (2 $\mathrm{min})$.

Spontaneous FM1-43 labeling. Presynaptic boutons were loaded with FM1-43 (5 $\mu \mathrm{M})$ in the presence of $1 \mu \mathrm{M}$ TTX for $15 \mathrm{~min}$ at $32^{\circ} \mathrm{C}$ followed by a $30 \mathrm{~min}$ washout period. 

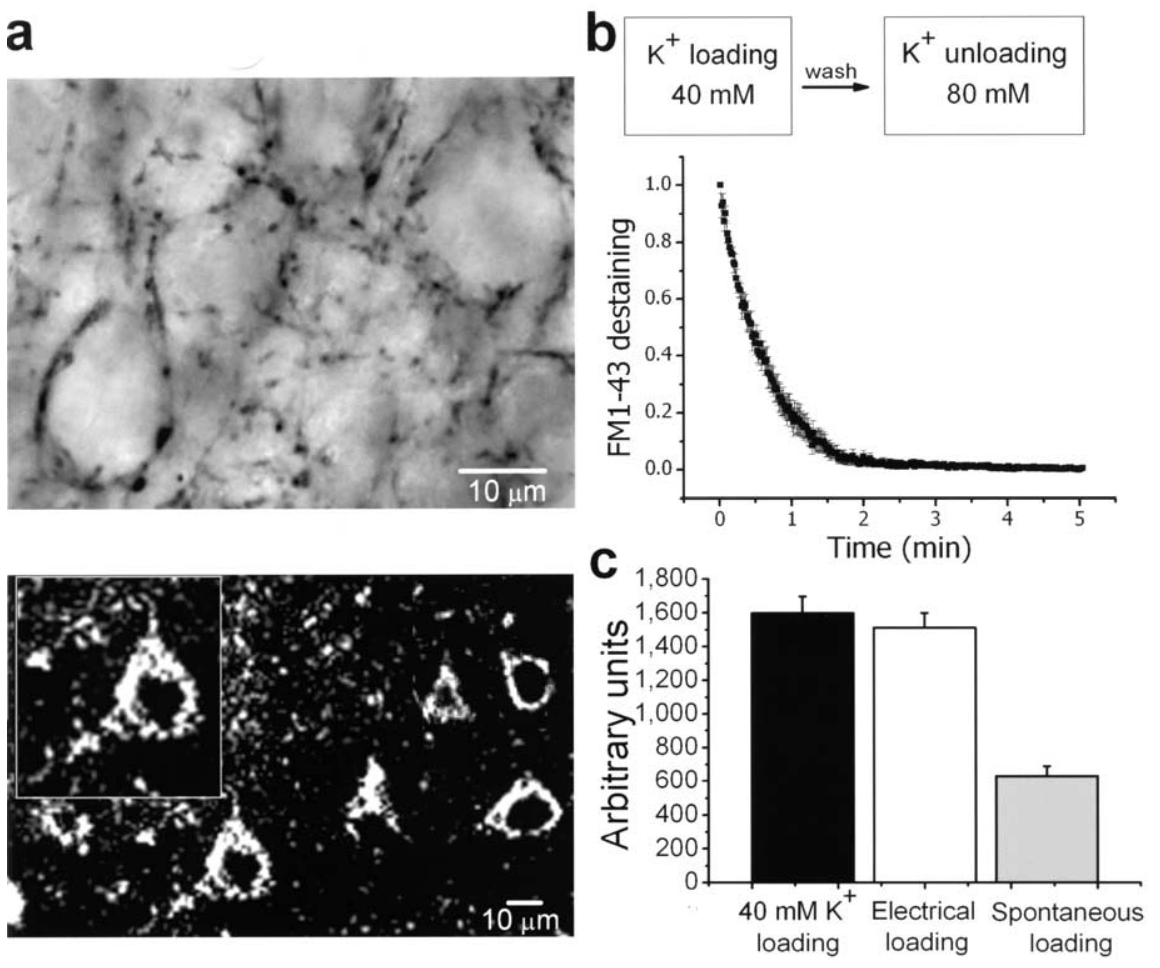

Figure 2. FM1-43 labeling of inhibitory terminals in rat neocortical slices. $\boldsymbol{A}$, Top, Representative photomicrograph showing parvalbumin immunoreactivity. Parvalbumin positive puncta decorating layer III pyramidal cell somata are shown. Bottom, Multiphoton imaging of an acute neocortical slice labeled with FM1-43, where the puncta surround the "ghosts" of pyramidal somata. $\boldsymbol{B}$, Fluorescence from terminals loaded with FM1-43 with a solution containing $40 \mathrm{~mm} \mathrm{~K}^{+}$showed a biexponential decay rate when challenged with an $80 \mathrm{~mm} \mathrm{~K}^{+}$destaining solution. C, FM1-43 fluorescence intensities obtained with three different loading paradigms. $\mathrm{K}^{+}(40 \mathrm{~mm})$ was used to load the total recycling pool. Electrical stimulation of afferent fibers $(10 \mathrm{~Hz}, 900 \mathrm{AP})$ loaded $95 \%$ of that total recycling pool, whereas spontaneous loading stained only $38 \%$ of the total recycling pool.

\section{Multiphoton excitation microscopy}

FM1-43 fluorescent images were collected with a $60 \times, 0.9 \mathrm{NA}$ waterimmersion objective (LUMPlanFI/IR2; Olympus, Melville, NY) using a custom-built multiphoton laser scanning microscope consisting of an upright Olympus BX50WI microscope and a modified FV300 scanhead. A Ti-sapphire laser pumped by a $10 \mathrm{~W}$ solid-state Ar laser (Chameleon; Coherent, Santa Clara, CA) was tuned to $840 \mathrm{~nm}$ center wavelength. Infrared-filtered FM1-43 fluorescence emission was detected by an external photomultiplier (R3896; Hamamatsu) in nondescanned mode. Infrared laser intensity was controlled by an external Pockels cell (Conoptics, Danbury, CT) before entering the scanhead. The lowest intensity necessary for adequate signal-to-noise ratio was used to avoid photodamage and FM1-43 bleaching. Average power in the back focal plane of the objective never exceeded $50 \mathrm{~mW}$. Laser-scanning and timelapse image acquisitions were controlled by FluoView-Tiempo software (Olympus).

Full frame images $(512 \times 512$ pixels, $\sim 72 \times 72 \mu \mathrm{m})$ were acquired every $1.1 \mathrm{~s}$. All image fields were obtained from within $\sim 200 \mu \mathrm{m}$ of the slice surface, typically $\sim 25-150 \mu \mathrm{m}$ deep. Ten image frames were acquired before stimulation and used to determine baseline fluorescence $\left(F_{\mathrm{b}}\right)$. After 10 frames, stimulation was delivered, and changes in FM1-43 emission intensity were expressed as $\Delta F / F_{\mathrm{b}}$. FM1-43 bleaching was measured by image sequences of similar duration but without stimulation. FM1-43 fluorescence intensity was measured from visually identified puncta or clusters of several puncta that could be individually tracked in a single $z$-plane (focal) section over time. The fluorescence intensity of each of these regions-of-interest (ROIs) was individually measured, normalized and plotted over time, after background and bleaching subtraction (Stanton et al., 2001; Zakharenko et al., 2001; Axmacher et al., 2004; Tyler et al., 2006). Fluorescence changes over time in single puncta were analyzed using ImageJ (Abramoff et al., 2004). All data analyses were performed blindly and included only those FM1-43 puncta whose fluo- rescence intensity was more than two times the SD of the baseline FM1-43 fluorescence intensity (Zakharenko et al., 2001). Identical ROIs with a constant diameter of $1 \mu \mathrm{m}$ (seven pixels) were used to select individual puncta and ensure consistent analysis over time and regions in a slice. Data from experiments where lateral displacement $(x-y)$ or focal drift in the $z$-axis of FM1-43 puncta occurred, were discarded. To avoid imaging nonselective FM1-43 staining, only puncta that showed stimulus-dependent destaining were included in the analyses. Statistical analyses of imaging data were performed using Student's two-tailed t tests, using the number of slices as " $n$ " unless stated otherwise. Experimental results are represented as mean \pm SEM.

Lateral bouton movement has been reported to be a substantial problem when imaging over long periods of time (30 min) (Groemer and Klingauf, 2007). To avoid this complication, our imaging sessions were $5 \mathrm{~min}$ in length. Any boutons that showed lateral movement were not analyzed. It has been suggested that potential artifacts are introduced by normalization of FM1-43 destaining curves which tend to show minimal to no destaining when expressed as raw fluorescence intensity values (Groemer and Klingauf, 2007). In our experiments, data that were obtained after spontaneous loading showed a linear decay before and after normalization (i.e., $\Delta F / F_{\mathrm{b}}$ ). The decay of raw fluorescence intensity from individual ROIs showed linear rates before normalization of data (after bleaching correction). The similar rates of destaining observed before and after data normalization, indicate that our data were not affected by these data transformations.

\section{Parvalbumin staining in rat neocortex}

Animals were deeply anesthetized and perfused with saline followed by a fixative solution containing $1 \%$ paraformaldehyde and $0.25 \%$ glutaraldehyde (in PBS) for $20 \mathrm{~min}$. After cryoprotection in 30\% sucrose (in PBS), $50-\mu \mathrm{m}$-thick sections were prepared with a Vibratome. Sections were incubated in anti-parvalbumin antibodies (1:4000; Millipore, Temecula, CA) for $24 \mathrm{~h}$ at room temperature. After washing, sections were incubated in a biotinylated secondary antibody for $1 \mathrm{~h}$, followed by avidin-biotin-peroxidase for $90 \mathrm{~min}$. Sections were imaged using a CCD camera (QICAM; Qimaging, Burnaby, British Columbia, Canada) on a Leica DMRB microscope.

\section{Results}

We first examined the facilitatory effect of KA on IPSCs using whole-cell patch-clamp recordings from layer II/III pyramidal neurons in prefrontal cortex slices. Cell identification was confirmed by intracellular labeling. A camera lucida reconstruction of a biocytin-labeled pyramidal cell is shown in Figure $1 A$. Recordings of evoked IPSCs (Fig. $1 B, C$ ) showed that bath application of $250 \mathrm{~nm}$ KA increased IPSC amplitude. Similar increases were seen in all cells tested $(n=13)$. The frequency of miniature IPSCs (mIPSCs) was increased by KA, whereas their amplitude was unaffected (Fig. $1 D-G$ ). Similar changes in mIPSC frequency were seen in all cells tested $(n=$ 13). These results suggest that KA acts presynaptically to increase spontaneous GABA release in the upper layers of rat prefrontal cortex.

Inhibitory nerve terminals of parvalbumin-positive fast- 

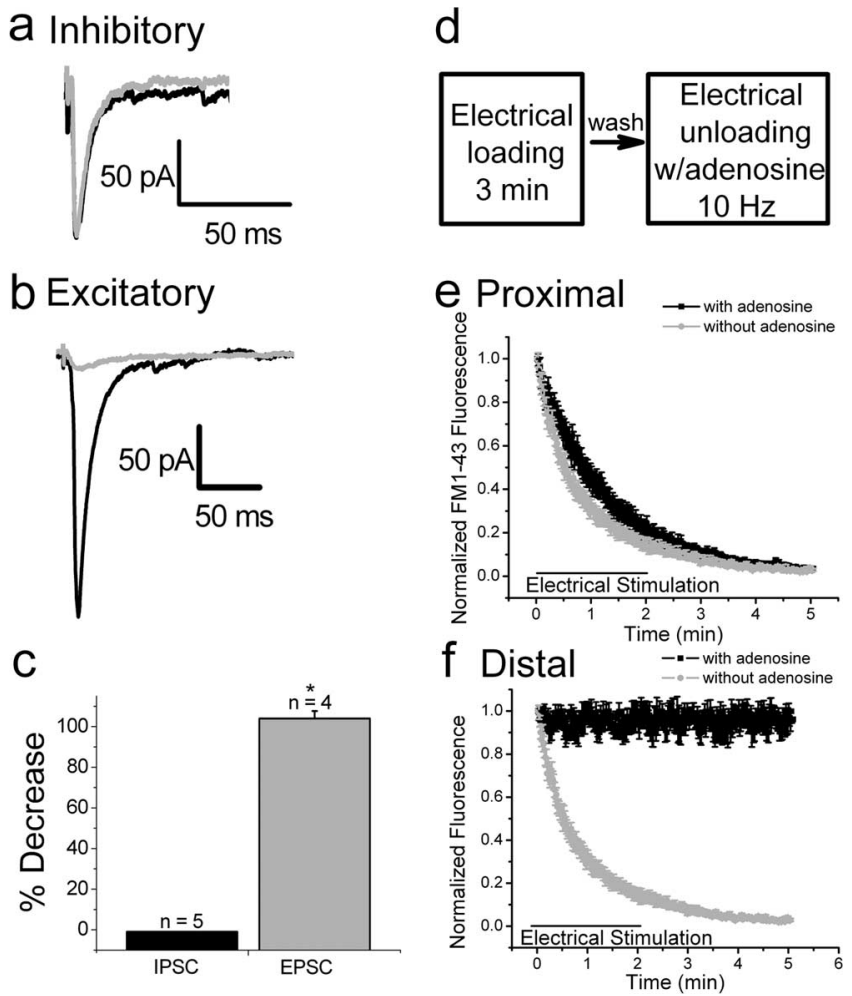

Figure 3. Adenosine inhibits glutamate but not GABA release. $A$, IPSCs evoked before (black trace) and after (gray trace) bath application of $50 \mu \mathrm{m}$ adenosine. Each trace is an average of 10 trials. Adenosine had no effect on the amplitude of evoked IPSCS. $\boldsymbol{B}$, EPSCs evoked before (black trace) and after (gray trace) bath application of adenosine (50 $\mu \mathrm{m})$. EPSCs were significantly reduced by adenosine. $\boldsymbol{C}$, Bar graphs illustrating the percentage decrease of evoked IPSC and EPSC amplitudes after application of adenosine. D, Experimental protocol used for electrical loading and unloading of FM1-43 in presynaptic terminals. $\boldsymbol{E}$, Destaining of FM1-43 labeled proximal, perisomatic puncta was not affected in the presence of adenosine $(50 \mu \mathrm{m})$ (black trace; compare with Fig. $3 b$, control trace). $\boldsymbol{F}$, Distal FM1-43 puncta did not destain in the presence of adenosine. ${ }^{*} p=0.001$.

spiking interneurons synapse onto pyramidal cell somata and proximal dendrites (Kawaguchi and Kubota 1998a,b). Parvalbumin-positive puncta outlining pyramidal neuron cell bodies are shown in Figure 2A (top); an FM1-43 labeled slice imaged by multiphoton excitation microscopy ( $840 \mathrm{~nm}$ excitation) is also shown (Fig. 2A, bottom). Proximal FM1-43 puncta on somata loaded and destained using a high $\mathrm{K}^{+}$solution had typical biexponential decay rates (Fig. $2 B$ ). Figure $2 C$ shows that electrically induced FM1-43 loading produced staining comparable with that obtained with $40 \mathrm{mM} \mathrm{K}^{+}$stimulation (i.e., $95 \%$ of total recycling pool). In contrast, allowing the staining with FM1-43 to proceed by action potential (AP) independent activity (i.e., in the presence of TTX) yielded labeling of only $38 \%$ of the total recycling pool.

These presumptive inhibitory terminals distributed around pyramidal cell somata (Brager et al., 2003; Axmacher et al., 2004) were chosen for subsequent analyses of FM1-43 initial fluorescence intensity and destaining kinetics. To further identify these terminals as inhibitory, we made use of the sensitivity of glutamate release to inhibition by adenosine. Adenosine inhibits glutamate, but not GABA, release in the hippocampus (Lambert and Teyler, 1991; Thompson et al., 1992). We confirmed this differential effect in the neocortex. Bath application of $50 \mu \mathrm{M}$ adenosine had no effect on the amplitude of evoked IPSCs (Fig. $3 A, C$ ), whereas evoked EPSC amplitudes were significantly decreased
(Fig. 3 B, C). Using FM1-43 imaging, boutons in slices of prefrontal cortex were loaded using $10 \mathrm{~Hz}$ stimulation in control ACSF, and destained in the presence and absence of $50 \mu \mathrm{M}$ adenosine (Fig. 3D). In complete agreement with the intracellular recordings, adenosine did not affect FM1-43 destaining from puncta surrounding pyramidal cell somata (Fig. $3 E$ ), whereas it completely prevented FM1-43 destaining from distal puncta (Fig. $3 F$ ). These findings provide additional evidence indicating that proximal puncta on somata are inhibitory and more distal puncta are excitatory.

Once we established that proximal FM1-43 puncta represent GABAergic terminals, we imaged them after FM1-43 loading with 900 afferent stimuli at $10 \mathrm{~Hz}$. After dye wash-out, FM1-43 destaining was evoked with $10 \mathrm{~Hz}$ stimulation (Fig. $1 \mathrm{~A}$, left). Under control conditions, FM1-43 destaining was well described by an exponential function with a time constant of $1.7 \pm 0.1 \mathrm{~min}$ $(n=25)$ (Fig. $4 B$ ). In the presence of 250 nm kainate, the destaining rate was significantly accelerated $(1.2 \pm 0.1 \mathrm{~min} ; n=25 ; p=$ 0.001) (Fig. 4B). Results are summarized in Figure $4 C$. These results directly demonstrate that kainate has a presynaptic facilitatory effect on transmitter release from perisomatic inhibitory terminals onto cortical pyramidal neurons in the prefrontal cortex.

Spontaneous release of neurotransmitter in the absence of action potentials is a common feature of synapses. It has been recently suggested that a distinct vesicle pool underlies spontaneous release in cultured hippocampal neurons (Sara et al., 2005). In the next series of experiments, we allowed FM1-43 uptake to proceed by spontaneous vesicular recycling for 15 min in the presence of TTX (Fig. $4 A$, middle). After dye washout, clearly resolved FM1-43 puncta outlining pyramidal neuron somata were observed, similar to those observed after electrical- or high $\mathrm{K}^{+}$-induced labeling. AP independent destaining of this spontaneously loaded pool in the presence of TTX showed a slow, linear decay (Fig. $4 D, E$ ), reminiscent of the kinetic behavior of a reluctant vesicle pool observed in excitatory synapses between cultured hippocampal neurons (Sara et al., 2005). Spontaneously loaded and unloaded vesicles had destaining profiles best fit by a linear regression. The rate of destaining from the spontaneous pool was also increased by KA, although still linear in nature [slope $(m)=$ -0.04537 control vs $-0.06168 \mathrm{KA}]$. Intriguingly, when terminals were loaded with FM1-43 by spontaneous activity in the absence of TTX and subsequently destained by a $10 \mathrm{~Hz}$ afferent stimulation (Fig. 4A, right), KA did not affect the rate of FM1-43 destaining $(3.03 \pm 0.3 \mathrm{~min}$ control vs kainate $2.9 \pm$ 0.2 min; $n=17, p=0.5$ ) (Fig. $4 F, G$ ). The initial exponential rate of destaining presumably reflects release from vesicles that were loaded after action potential-dependent release (i.e., after a spontaneous IPSC). The subsequent linear rate of release is presumably attributable to release of vesicles that were loaded independently of action potentials (i.e., after a miniature IPSC), similar to results seen in Figure 4, D and E. Together, these results demonstrate that KA selectively enhances release from vesicle pools which are loaded and unloaded using matching dye loading protocols, but not from vesicle pools which are loaded and then subsequently unloaded by mismatching protocols (i.e., spontaneous or evoked).

\section{Discussion}

This study examined GABA release from presynaptic nerve terminals in rat neocortical slices by directly imaging vesicular recycling with the styryl dye FM1-43 and multiphoton excitation 


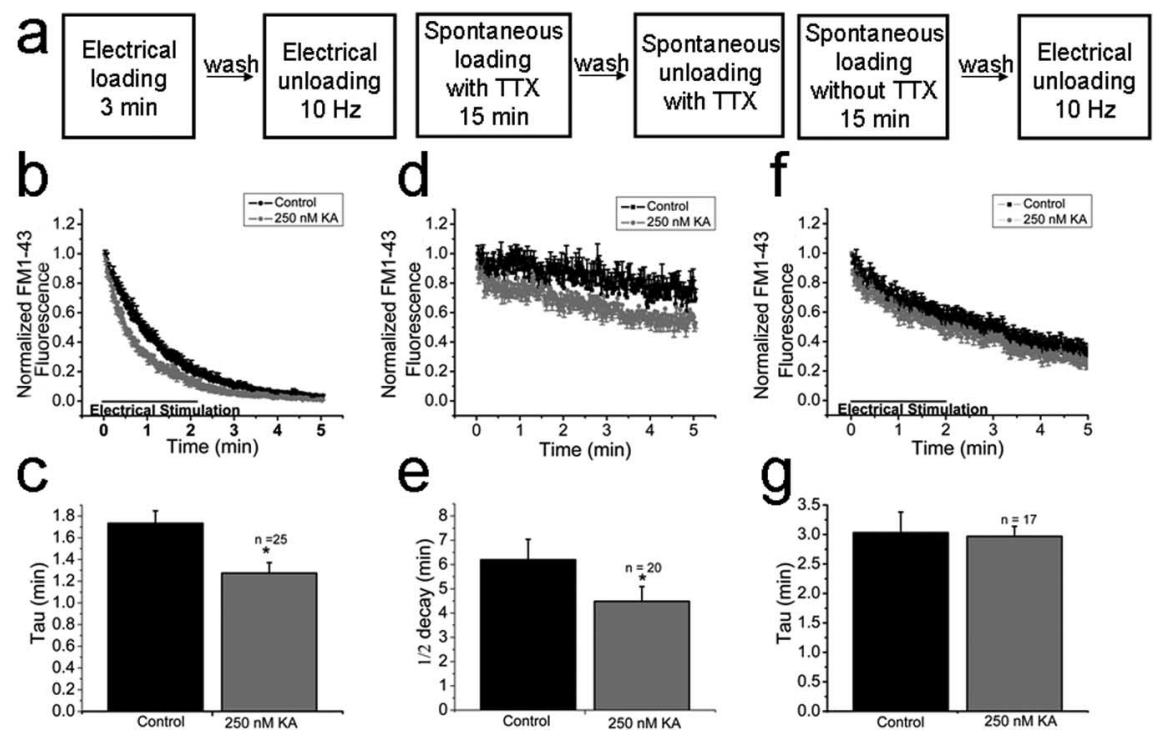

Figure 4. Effects of KA on FM1-43 destaining kinetics. $A$, Experimental protocol used for loading and unloading presynaptic terminals. $\boldsymbol{B}$, Ten hertz afferent stimulation evoked rapid destaining. Similar stimulation in the presence of $250 \mathrm{~nm} \mathrm{KA}$ accelerated the rate of destaining. $\boldsymbol{C}$, Summary histogram showing decay times under control conditions and in presence of KA. D, Vesicles spontaneously loaded and spontaneously unloaded in the presence of TTX show slow monotonic destaining. KA significantly increased the destaining rate. $\boldsymbol{E}$, Summary histogram showing that KA changed FM1-43 destaining rates. $\boldsymbol{F}$, KA does not enhance destaining of spontaneously loaded but electrically unloaded vesicles. G, Summary histogram showing that KA did not change FM1-43 destaining rates. Control error bars are in the positive direction whereas KA error bars are represented in the negative direction. ${ }^{*} p=0.001$.

microscopy. FM1-43 destaining has been used previously to study evoked (Brager et al., 2003) and spontaneous (Axmacher et al., 2004) vesicular release from identified GABAergic terminals in hippocampal slices. It was found that spontaneous vesicular release was shown to be negatively modulated by presynaptic $\mathrm{GABA}_{\mathrm{A}}$ receptors (Axmacher et al., 2004) and that evoked GABA release could be decreased, via different mechanisms, by presynaptic cannabinoid and $\mathrm{GABA}_{\mathrm{B}}$ receptors (Brager et al., 2003). The present results provide direct evidence that KAR activation facilitates inhibitory synaptic transmission in prefrontal cortex by increasing presynaptic GABA release. We also provide the first evidence of distinct vesicle pools within inhibitory nerve terminals in neocortical slices that exhibit differential destaining kinetics depending on activity patterns (i.e., spontaneous or evoked).

Consistent with the observations of Sara et al. (2005) in hippocampal excitatory terminals in culture, FM1-43 uptake during spontaneous vesicle recycling labels a vesicle pool within neocortical inhibitory nerve terminals that is released much more slowly than terminals loaded by electrical or high $\mathrm{K}^{+}$stimulation. The basis for the discrepancy regarding the issue of whether a single pool of vesicles is responsible for activity-dependent and spontaneous release (Groemer and Klingauf, 2007) or not (Sara et al., 2005) is still unclear. However, the differential modulation by presynaptic KARs shown in the present experiments supports the interpretation of two vesicle pools defined based on their mode of endocytosis (Ashery et al., 2000). Glutamate synapses exhibit more variability in vesicle release than GABA synapses (Molder et al., 2007). Analysis of individual puncta yielded rates of destaining similar to those for clusters. This suggests that different populations of terminals with different rates were not sampled. Rather, two different pools of synaptic vesicles were present. Our results support the view that distinct vesicle pools exist in central presynaptic inhibitory terminals. These pools are engaged during different levels and/or patterns of neuronal activity (i.e., spontaneous or evoked), and these distinct pools are preserved by the ensuing vesicle recycling process.

Spontaneous IPSCs are a mixture of events caused by action potentialdependent release and "true" quantal miniature events (mIPSCs). We found that terminals loaded spontaneously in the presence of TTX destain with a linear profile in the absence of action potentials (i.e., in TTX). We also found that when vesicles are allowed to load spontaneously, but in the absence of TTX, subsequent electrical unloading shows both exponential as well as linear rates of FM dye destaining. We interpret these results to mean that the exponential rates of FM destaining reflect the fusion of vesicles loaded during spontaneous action potentials, whereas the linear rates of FM destaining reflect the release from vesicles loaded independently of action potential firing. The slower rate of FM destaining suggests that vesicles loaded in the absence of action potentials are more reluctant to release by afferent stimulation. In addition, release from vesicles spontaneously loaded in TTX is enhanced by KA. However, terminals stained by spontaneous action potentials and destained by afferent stimulation are insensitive to KA modulation. We interpret that vesicles that are recycled spontaneously and those that are recycled during neuronal activity belong to separate synaptic vesicle pools. Our results suggest that, under physiological conditions, KA would facilitate release from both pools. It will be intriguing to determine whether other presynaptic modulators (e.g., GABA, NMDA, adenosine, BDNF) can selectively modulate these putative distinct vesicle pools.

Both inhibitory and excitatory synapses responsible for forming the connections in local neocortical circuits show marked short-term plasticity (Varela et al., 1997, 1999; Galarreta and Hestrin, 1998; Hempel et al., 2000; Watanabe et al., 2005). This short-term plasticity can influence network activity (Thomson and Deuchars, 1994; Tsodyks and Markram, 1997) and alter cortical responses to sensory inputs (Fanselow and Nicolelis, 1999). The most common form of synaptic plasticity is short-term depression. During paired-pulse or repetitive activation in the neocortex, excitatory (Thomson et al., 1993; Markram and Tsodyks, 1996; Varela et al., 1997) and inhibitory (Deisz and Prince, 1989; Thomson et al., 1996; Reyes et al., 1998) synapses show frequency-dependent depression. The relative amount of depression is variable, with EPSCs showing a stronger reduction in response to sustained activation than IPSCs (Galarreta and Hestrin, 1998; Varela et al., 1999), resulting in circuit stabilization. Short-term depression is generally attributed to presynaptic changes in the pool of releasable vesicles (Liu and Tsien, 1995; von Gersdorff and Matthews, 1997; Klingauf et al., 1998; Silver et al., 1998). The present findings suggest that facilitation of vesicular release by 
kainate receptor activation could limit depression and help to maintain effective levels of cortical inhibition.

\section{References}

Abramoff MD, Magelhaes PJ, Ram SJ (2004) "Image Processing with ImageJ". Biophotonics International 11:36-42.

Ali AB, Rossier J, Staiger JF, Audinat E (2001) Kainate receptors regulate unitary IPSCs elicited in pyramidal cells by fast-spiking interneurons in the neocortex. J Neurosci 21:2992-2999.

Ashery U, Varoqueaux F, Voets T, Betz A, Thakur P, Koch H, Neher E, Brose N, Rettig J (2000) Munc13-1 acts as a priming factor for large densecore vesicles in bovine chromaffin cells. EMBO J 19:3586-3596.

Axmacher N, Winterer J, Stanton PK, Draguhn A, Muller W (2004) Twophoton imaging of spontaneous vesicular release in acute brain slices and its modulation by presynaptic $\mathrm{GABA}_{\mathrm{A}}$ receptors. NeuroImage 22:1014-1021.

Brager DH, Luther PW, Erdelyi F, Szabo G, Alger BE (2003) Regulation of exocytosis from single visualized GABAergic boutons in hippocampal slices. J Neurosci 23:10475-10486.

Braitenberg V, Schuz A (1991) Anatomy of the cortex. Berlin: Springer.

Ceccarelli B, Fesce R, Grohovaz F, Haimann C (1988) The effect of potassium on exocytosis of transmitter at the frog neuromuscular junction. J Physiol (Lond) 401:163-183.

Constantinidis C, Williams GV, Goldman-Rakic PS (2002) A role for inhibition in shaping the temporal flow of information in prefrontal cortex. Nat Neurosci 5:175-180.

Cossart R, Tyzio R, Dinocourt C, Esclapez M, Hirsch JC, Ben-Ari Y, Bernard C (2001) Presynaptic kainate receptors that enhance the release of GABA on CA1 hippocampal interneurons. Neuron 29:497-508.

Deisz RA, Prince DA (1989) Frequency-dependent depression of inhibition in guinea-pig neocortex in vitro by $\mathrm{GABA}_{\mathrm{B}}$ receptor feed-back on $\mathrm{GABA}$ release. J Physiol (Lond) 412:513-541.

Douglas RJ, Koch C, Mahowald M, Martin KAC, Suarez HH (1995) Recurrent excitation in neocortical circuits. Science 269:981-985.

Elmqvist D, Quastel DM (1965) A quantitative study of end-plate potentials in isolated human muscle. J Physiol (Lond) 178:505-529.

Fanselow EE, Nicolelis MAL (1999) Behavioral modulation of tactile responses in the rat somatosensory system. J Neurosci 19:7603-7616.

Frerking M, Petersen CC, Nicoll RA (1999) Mechanisms underlying kainate receptor-mediated disinhibition in the hippocampus. Proc Natl Acad Sci USA 96: 12917-12922.

Galarreta M, Hestrin S (1998) Frequency-dependent synaptic depression and the balance of excitation and inhibition in the neocortex. Nat Neurosci 1:587-594.

Gonzalez-Islas C, Hablitz JJ (2001) Dopamine inhibition of evoked IPSCs in rat prefrontal cortex. J Neurophysiol 86:2911-2918.

Groemer TW, Klingauf J (2007) Synaptic vesicles recycling spontaneously and during activity belong to the same vesicle pool. Nat Neurosci 10:145-147.

Hempel CM, Hartman KH, Wang X-J, Turrigiano GG, Nelson SB (2000) Multiple forms of short-term plasticity at excitatory synapses in rat medial prefrontal cortex. J Neurophysiol 83:3031-3041.

Kawaguchi Y, Kubota Y (1998a) GABAergic cell subtypes and their synaptic connections in rat frontal cortex. Cereb Cortex 7:476-486.

Kawaguchi Y, Kubota Y (1998b) Neurochemical features and synaptic connections of large physiologically-identified GABAergic cells in the rat frontal cortex. Neuroscience 85:677-701.

Klingauf J, Kavalali ET, Tsien RW (1998) Kinetics and regulation of fast endocytosis at hippocampal synapses. Nature 394:581-585.

Lambert NA, Teyler TJ (1991) Adenosine depresses excitatory but not fast inhibitory synaptic transmission in area CAl of the rat hippocampus. Neurosci Lett 122:50-52.

Liu G, Tsien RW (1995) Properties of synaptic transmission at single hippocampal synaptic boutons. Nature 375:404-408.

Markram H, Sakmann B (1994) Calcium transients in dendrites of neocortical neurons evoked by single subthreshold excitatory postsynaptic potentials via low-voltage-activated calcium channels. Proc Natl Acad Sci USA 91:5207-5211.

Markram H, Tsodyks M (1996) Redistribution of synaptic efficacy between neocortical pyramidal neurons. Nature 382:807-810.

Mathew S, Hablitz JJ (2003) Kainate receptors modulate inhibitory synaptic transmission in rat neocortex. Soc Neurosci Abstr 29:803.10.
Mathew S, Hablitz JJ (2005) Modulation of inhibitory synaptic transmission in the neocortex of GluR6 knock-out mice. Soc Neurosci Abstr 31:40.8.

Min MY, Melyan Z, Kullmann DM (1999) Synaptically released glutamate reduces gamma-aminobutyric acid (GABA)ergic inhibition in the hippocampus via kainate receptors. Proc Natl Acad Sci USA 96:9932-9937.

Moulder KL, Jiang X, Taylor AA, Shin W, Gillis KD, Mennerick S (2007) Vesicle pool heterogeneity at hippocampal glutamate and GABA synapses. J Neurosci 27:9846-9854.

Mulle C, Sailer A, Swanson GT, Brana C, O'Gorman S, Bettler B, Heinemann SF (2000) Subunit composition of kainate receptors in hippocampal interneurons. Neuron 28:475-484.

Murthy VN, Stevens CF (1999) Reversal of synaptic vesicle docking at central synapses. Nat Neurosci 2:503-507.

Nelson SB, Turrigiano GG (1998) Synaptic depression: a key player in the cortical balancing act. Nat Neurosci 1:539-541.

Pinheiro PS, Rodrigues RJ, Rebola N, Xapelli S, Oliveira CR, Malva JO (2005) Presynaptic kainate receptors are localized close to release sites in rat hippocampal synapses. Neurochem Int 47:309-316.

Pyle JL, Kavalali ET, Piedras-Renteria ES, Tsien RW (2000) Rapid reuse of readily releasable pool vesicles at hippocampal synapses. Neuron 28:221-231.

Prange O, Murphy TH (1999) Correlation of miniature synaptic activity and evoked release probability in cultures of cortical neurons. J Neurosci 19:6427-6438.

Ren M, Yoshimura Y, Takada N, Horibe S, Komatsu Y (2007) Specialized inhibitory synaptic actions between nearby neocortical pyramidal neurons. Science 316:758-761.

Reyes A, Lujan R, Rozov A, Burnashev N, Somogyi P, Sakmann B (1998) Target-cell-specific facilitation and depression in neocortical circuits. Nat Neurosci 1:279-285.

Richards DA, Guatimosin C, Rizzoli SO, Betz WJ (2003) Synaptic vesicle pools at the frog neuromuscular junction. Neuron 39:529-541.

Rodriguez-Moreno A, Herreras O, Lerma J (1997) Kainate receptors presynaptically downregulate GABAergic inhibition in the rat hippocampus. Neuron 19:893-901.

Rosenmund C, Stevens CF (1996) Definition of the readily releasable pool of vesicles at hippocampal synapses. Neuron 16:1197-1207.

Sara Y, Virmani T, Deak F, Liu X, Kavalali ET (2005) An isolated pool of vesicles recycles at rest and drives spontaneous neurotransmission. Neuron 45:563-573.

Scheller RH (1995) Membrane trafficking in the presynaptic nerve terminal. Neuron 14:893-897.

Schneggenburger R, Meyer AC, Neher E (1999) Released fraction and total size of a pool of immediately available transmitter quanta at a calyx synapse. Neuron 23:399-409.

Silver RA, Momiyama A, Cull-Candy SG (1998) Locus of frequencydependent depression identified with multiple-probability fluctuation analysis at rat climbing fibre-Purkinje cell synapses. J Physiol (Lond) 510:881-902.

Sompolinsky H, Shapley R (1997) New perspectives on the mechanisms for orientation selectivity. Curr Opin Neurobiol 7:514-522.

Stanton PK, Heinemann U, Müller W (2001) FM1-43 imaging reveals cGMP-dependent long-term depression of presynaptic transmitter release. J Neurosci 21:RC167.

Stevens CF, Tsujimoto T (1995) Estimates for the pool size of releasable quanta at a single central synapse and for the time required to refill the pool. Proc Natl Acad Sci USA 92:846-849.

Thomson AM, Deuchars J (1994) Temporal and spatial properties of local circuits in neocortex. Trends Neurosci 17:119-126.

Thomson AM, Deuchars J, West DC (1993) Large, deep layer pyramidpyramid single axon EPSPs in slices of rat motor cortex display paired pulse and frequency-dependent depression, mediated presynaptically and self-facilitation, mediated postsynaptically. J Neurophysiol 70:2354-2369.

Thomson AM, West DC, Hahn J, Deuchars J (1996) Single axon IPSPs elicited in pyramidal cells by three classes of interneurons in slices of rat neocortex. J Physiol (Lond) 496:81-102.

Thompson SM, Haas HL, Gahwiler BH (1992) Comparison of the actions of adenosine at pre- and postsynaptic receptors in the rat hippocampus in vitro. J Physiol (Lond) 451:347-363. 
Tsodyks MV, Markram H (1997) The neurol code between neocortical pyramidal neurons depends on neurotransmitter release probability. Proc Natl Acad Sci USA 94:719-723.

Tyler WJ, Zhang Xl, Hartman K, Winterer J, Muller W, Stanton PK, PozzoMiller L (2006) BDNF increases release probability and the size of a rapidly recycling vesicle pool within rat hippocampal excitatory synapses. J Physiol (Lond) 574:787-803.

Varela JA, Sen K, Gibson J, Fost J, Abbott LF, Nelson SB (1997) A quantitative description of short-term plasticity at excitatory synapses in layer $2 / 3$ of rat primary visual cortex. J Neurosci 17:7926-7940.

Varela JA, Song S, Turrigiano GG, Nelson SB (1999) Differential depression at excitatory and inhibitory synapse in visual cortex. J Neurosci 19:4293-4304. von Gersdorff H, Matthews G (1997) Depletion and replenishment of vesicle pools at a ribbon-type synaptic terminal. J Neurosci 17:1919-1927.

Watanabe J, Rozov A, Wollmuth LP (2005) Target-specific regulation of synaptic amplitudes in the neocortex. J Neurosci 25:1024-1033.

Zakharenko SS, Zablow L, Siegelbaum SA (2001) Visualization of changes in presynaptic function during long-term synaptic plasticity. Nat Neurosci 4:711-717.

Zhou FM, Hablitz JJ (1999a) Dopamine modulation of membrane and synaptic properties of interneurons in rat cerebral cortex. J Neurophysiol 81:967-976.

Zhou FM, Hablitz JJ (1999b) Activation of serotonin receptors modulates synaptic transmission in rat cerebral cortex. J Neurophysiol 82:29892999. 